\title{
A HISTÓRIA DA EDUCAÇÃO E DA EDUCAÇÃO FÍSICA: OLHARES PARA A FORMAÇÃO E SUAS PESQUISAS
}

\author{
Andressa Aita Ivo \\ Franciele Roos da Silva Ilha
}

\begin{abstract}
RESUMO
Este estudo busca realizar um estudo epistemológico da Educação/Educação Física, enfatizando a formação e o processo de pesquisa educacional. Tendo em vista que, acredita-se na importância de se saber sobre a trajetória da Educação/Educação Física junto à construção da humanidade. Concebendo esta nova sociedade com as influências da globalização, é preciso que a Educação/Educação Física supra as novas necessidades que se fazem presente na escola no desenvolvimento dos educandos. Entretanto, percebe-se que pelas escolhas que a sociedade vem fazendo, não estamos tão perto de atingir esse objetivo. Ainda que, muitos educadores venham desempenhando um excelente trabalho para alcançar essas metas, uma grande parte de profissionais ainda não se conscientizaram de tal necessidade. Dessa forma, o profissional da área de Educação precisa cumprir tem com as exigências que tem sobre si na construção e socialização de conhecimentos, habilidades e competências no cenário complexo do mundo contemporâneo com a tarefa de participar como docente, pesquisador e gestor do processo de formação de crianças, jovens e adultos.
\end{abstract}

\section{PALAVRAS-CHAVE}

História; Educação; Educação física; Formação; Pesquisa

\section{THE EDUCATION AND PHYSICAL EDUCATION HISTORY: VIEWS FOR THE FORMATION AND ITS RESEARCHES}

\begin{abstract}
This work is aimed to make a epistemological research about Education/Physical Education, emphasizing the formation and the proccess of educational research. In face of these situation, we believe in the importance of knowing about the Education/Physical Education trajectory in relation to the development of humanity. Conceiving this new society with the influencies of globalization, it is necessary that Education/Physical Education provides the necessities from school in the development of students. However, according to the choices made by the society, it is possible to notice that we are not close to reach this aim. Even that many educators have developed an excellent work to reach these objectives, a great number of professionals do not admit these necessity. Thus, the professional from the field of Education needs to carry the exigencies about himself out in the construction and socialization of knowledges, abilities and competencies in the complex cenary of the contemporary world. Also, it is important to participate as docent, researcher and gestor of the formation proccess of children, teenagers and adults.
\end{abstract}

\section{KEYWORDS}

History; Education; Physical education; Formation; Research 


\section{CONTEXTUALIZAÇÃO DA TEMÁTICA}

Ao longo do processo construtivo na qual a Educação perpassa, ela apresenta características próprias em cada época, bem como traz consigo em sua prática a cultura presente nas diferentes sociedades, por isso é tão complexa e apresenta-se com múltiplas dimensões merecedoras de serem estudadas.

Um tema de destaque, que vem sendo amplamente debatido no campo da Educação, trata-se da formação de professores. Esta que, para muitos ainda parece limitar-se a conclusão do curso de graduação. No entanto, quando objetiva-se um constante desenvolvimento profissional é necessário dar seguimento aos estudos, articulando os conhecimentos adquiridos na formação inicial com a prática pedagógica na construção dos saberes docente.

Para atingir tais metas na formação é imprescindível um processo de ensino fundamentado e contextualizado com a realidade do aluno, buscando mostrar a importância da pesquisa no campo educacional. Nesse contexto formativo, várias são as inquietações que surgem ao longo do processo em decorrência da contínua problemática existente no meio educacional. Dessa forma, faz-se necessário pontuar algumas questões históricas, políticas e sociais que desencadearam tal situação.

Nesse sentido, este estudo busca realizar um estudo epistemológico da Educação/Educação Física, enfatizando a formação e o processo de pesquisa educacional. Sendo assim, acredita-se na importância de se saber sobre a trajetória da Educação/Educação Física junto à construção da humanidade, pois a filosofia, a história e a sociologia, oferecem os elementos básicos para que se compreenda as atitudes docentes e se possa transformá-las em prol da efetiva aprendizagem dos alunos.

Em relação aos procedimentos metodológicos, este estudo apresenta a abordagem qualitativa, que segundo Gamboa (1995, p.61) “proporciona a busca de novas alternativas para o conhecimento de uma realidade tão dinâmica e polifacética como a problemática estudada”. Sendo do tipo revisão bibliográfica que, como descreve Carvalho (1987, p.110) “é a atividade de localização e consulta de fontes diversas de informações escritas, para coletar dados gerais e específicos a respeito de determinado tema”. 


\section{DISCUSSÕES INICIAIS SOBRE O PROCESSO DE ENSINO}

Gadotti (1999) ao situar a Educação no Oriente identificou um ensino essencialmente prático e ligado a valores como a religião, baseado na imitação e na oralidade. Sendo que, a escola como instituição formal surgiu como resposta à divisão do trabalho e ao nascimento do Estado, da família e da propriedade privada.

Em relação à sociedade Grega, relata que esta foi o berço da cultura e da civilização oriental, devido a sua situação geográfica favorável, ao comércio e ao fato de ser sustentada por colônias estratificadas. Os gregos tinham uma visão universal de homem, porém sua forma de ensinar estimulava a competição, além de o ensino ser proporcionado apenas para a minoria da população (GADOTTI, 1999).

Em Roma a Educação, o autor salienta que esta foi utilitária e militarista, organizada pela disciplina e pela justiça. Já, na idade Feudal, temos uma continuidade no processo educacional, com pequenas inovações. A educação medieval ocorreu de acordo com os grandes acontecimentos da época, dos quais se ressalta a pregação cristã.

Pela primeira vez a escola tornou-se instrumento ideológico, neste momento surge um novo tipo histórico de Educação, na qual existia uma Educação para o povo, sendo esta catequética, e uma Educação para o clérigo humanista filosófico-teológico (GADOTTI, 1999).

Entretanto, segue o autor, foi com a Idade Média que surgiram as primeiras universidades, pois as idéias renascentistas influenciaram o processo educacional. A Educação renascentista preparava a formação do homem burguês, portanto ainda não chegava às massas populares. Na busca de reverter com essa realidade Manacorda (2000) mostra sua inquietude quando diz que a Modernidade tem o grande objetivo de educar todos os homens humanamente.

De acordo com Gadotti (1999), o Iluminismo educacional representou o fundamento da pedagogia burguesa, que até hoje insiste predominantemente na transmissão de conteúdos e na formação individualista. Assim, a burguesia percebeu a necessidade de 
oferecer instrução mínima para a classe trabalhadora, na tentativa de formar cidadãos disciplinados.

Com o surto das ciências naturais na Modernidade, o pensamento pedagógico positivista consolidou a concepção burguesa de Educação. Tendo este, características como um pensamento científico, neutro e conservador (GADOTTI, 1999).

A partir disto, surge o movimento popular socialista com o intuito, dentre outros, de acabar com as desigualdades de classe. Bem como, coloca Manacorda (2000) de constituir uma realidade social nova e transformadora de indivíduos totalmente desenvolvidos. Ou seja, formar identidades na interação entre o eu e a sociedade (HALL, 2005).

A Escola Nova ou “escolanovismo” como também ficou conhecida, tem como ponto de partida a Escola Tradicional, já vigente na época, a qual implantou um ensino através da pedagogia tradicional. Assim, a Escola Nova inicia seu movimento efetuando críticas a este modelo de ensino, esboçando uma nova forma de interpretar a Educação (SAVIANI, 2006). Além disso, desenvolveram-se tecnologias de ensino, centrando o processo educativo nos métodos e no aluno.

Ainda nos dias de hoje muito se questiona o ensino tradicional, porém essa concepção de ensino é desenvolvida na maioria das instituições educacionais: universidades, escolas, etc. Pois, nos parece que os membros da sociedade que possuem mais meios, estratégias e condições de investir numa mudança significativa na Educação, se interessam mais numa população alienada que não venha a intervir e criticar o sistema vigente.

Neste sentido, Freire (2007), relata sua preocupação com os processos de ensinoaprendizagem. O mesmo autor denomina a Educação vigente como sendo “bancária”, pois os educadores agem como depositantes de conteúdos de sua narração, e os educandos recebem os depósitos, os guardam e os arquivam.

Com isso, a Educação não passa de um ato de depositar, nesta visão de Educação não há criatividade, não há transformação, não há construção de saber. Pois, entendemos que só há saber na construção, reconstrução, na busca constante que o homem faz com o mundo e nas suas relações com os homens. Freire (2007) propõe uma Educação libertadora, na qual educador e educando, se façam ambos, concomitantemente, educadores e educandos. 


\section{A HISTÓRIA DA FORMAÇÃO E A BUSCA PELA QUALIDADE DA EDUCAÇÃO}

A preocupação com a qualidade da Educação e com os processos de ensinoaprendizagem nos contextos específicos, tem levado ao questionamento os modelos formativos dos professores, que pouco tem contribuído com as esperadas mudanças do trabalho dos mesmos. Se for certo que o trabalho dos professores nos contextos educativos não se reduz a sua formação inicial ou continuada, esta constitui um elemento de fundamental importância para o desenvolvimento de suas competências profissionais.

Tendo em vista a própria história da formação docente no Brasil, como destaca Saviane (2005), esta permanece pouco fundamentada e articulada no âmbito de suas próprias leis. Pois, a ambigüidade e as falhas de expressão sugerem várias interpretações por parte da sociedade e principalmente da população mais crítica.

Sobre a formação de professores, Garcia (1999) traz diferentes conceitos para este, através de diversos autores. O que demonstra o quanto é difícil formular um único conceito que o defina, entretanto, podemos observar alguns tópicos que caracterizam tal termo, como: atividade intencional, relacional e de intercâmbio, uma formação dupla onde se combinam a formação acadêmica com a formação pedagógica, uma formação que pretende estimular o professor a promover nos alunos uma aprendizagem significativa.

Ainda que, discutir essa temática requer buscar subsídios na sua história nos aspectos macro e micro que englobam o contexto educacional, político, social e econômico. Diante desse desafio, Pereira (2000) realiza esse movimento através da construção do livro: Formação de professores: pesquisas, representações e poder. Esse trabalho possui reflexões sobre o passado, o presente e o futuro, no entanto, muitas vezes, o autor depara-se com problemáticas que não estão se resolvendo ao longo dos anos. Por isso, serão destacados alguns pontos que poderão motivar projetos de transformação na formação inicial de professores.

Num primeiro momento, o autor traz a tona o debate sobre as pesquisas desenvolvidas no Brasil com o tema formação. Na década de 70 eram privilegiados estudos que envolvessem a dimensão técnica do processo formativo. Em resposta dessa realidade, foram surgindo ao final desta, movimentos de crítica, em busca de uma prática educativa 
transformadora. Nas palavras do autor: “A própria escola passa a ser vista como um espaço, em que novas idéias e mudanças podem ser iniciadas” (PEREIRA, 2000, p.17).

A partir dos anos 80, difundiu-se a formação do educador e a importância deste assumir um compromisso político em favor das classes populares. Nesse momento também ocorreram denúncias da crise da Educação em defesa de melhores condições de trabalho e salários dignos. Nesse sentido, Arroyo (1985 apud PEREIRA, 2000) levanta o questionamento sobre quem deforma o profissional do ensino? E diz que nos formamos professores na universidade, porém ao ingressarmos no mundo do trabalho sofremos uma deformação, já que todo o contexto não contribui nem dá condições de desenvolvimento profissional. Nessa direção, ainda são inquietantes várias dúvidas sobre a escolha da profissão professor. Essa decisão se dá por acreditar na vocação, se constitui em “bico”?

Em conseqüência disso, a função da escola e da Educação escolar são trazidas a debate a fim de se constituir uma identidade em torno dessa questão. Da mesma maneira em que se pensa na formação de professores ou de educadores? Como ressalta o autor sobre "a importância do professor em seu processo de formação conscientizar-se da função da escola na transformação da realidade social dos seus alunos e ter clareza da necessidade da prática educativa estar associada a uma prática social mais global” (PEREIRA, 2000, p.27).

Esse quadro do papel do professor e sua função na escola foram sendo pensados em dois âmbitos: que o professor tivesse o conhecimento científico de sua área e o conhecimento pedagógico para promover a aprendizagem dos alunos, ainda que sem dissociar-se do compromisso político. Porém, este último foi reduzido ao ato de falar sobre, sem a perspectiva de transformação social.

Teoria e prática e sua disjunção também são questões destacadas no livro, sendo um tema bastante discutido em toda área educacional. Ao mesmo tempo em que o professor pesquisador e sua prática reflexiva são reforçados como meio de qualificar a Educação e a formação do professor. Para Shön (apud PEREIRA, 2000, p.35) “quando o profissional reflete na ação, ele torna um pesquisador no contexto prático”. Reforça ainda, que “a reflexão-naação pode ser uma prática rigorosa e tornar-se um instrumento importante na atividade profissional”. 
Partindo desta perspectiva de formação de professores, observamos que para compreendermos tal termo, é preciso perceber este no contexto educacional, analisando também os sujeitos deste processo, ou seja, professor e aluno. Neste momento, surgem novos elementos neste estudo como o ensino, a aprendizagem e os saberes docentes. Porém, estes elementos devem ser pensados de forma integrada e interagindo entre si, ou podemos correr o risco de cada vez mais separar e desmembrar o processo educacional, fortalecendo as dicotomias existentes nas práticas educativas e os modelos de racionalidade técnica. Os quais de acordo com Pérez Gómez (1992) apresentam uma relação linear e mecânica entre o conhecimento científico-técnico e a prática na sala de aula.

Neste sentido, o professor assume um novo papel no processo de ensino, o que implica uma série de reflexões sobre o mesmo, assim, hoje muito se questiona sobre quais são os saberes docentes e os saberes envolvidos na prática pedagógica. Pereira (1998) aponta para o fato de existirem idéias preconcebidas sobre os saberes necessários ao ofício de ser professor destacando-as da seguinte forma: conhecer o conteúdo, ter talento, ter bom senso, seguir sua intuição, ter experiência e por fim ter cultura.

O autor continua suas reflexões alertando para o fato de que devemos estabelecer saberes profissionais específicos, e portanto vários saberes são mobilizados pelo professor. Assim, destacam-se os seguintes saberes: saber disciplinar, saber curricular, saber das ciências da educação, saber da tradição pedagógica, saber experiencial e o saber da ação pedagógica. Entretanto, apesar das pesquisas existentes sobre os saberes docentes, e a pratica pedagógica dos professores por aqueles que se preocupam com a Educação e os processos de ensino, atualmente vive-se um novo embate na Educação brasileira.

De acordo com Cunha (2004) os professores passaram a atender um novo papel nesta sociedade moderna, de modo que são agora mais uma peça chave na engrenagem montada para que o projeto político-econômico funcione. O principal papel do professor passou a ser atender aos parâmetros avaliativos propostos pelas políticas educacionais. Desta forma, pesquisar sobre o professor, seus saberes e os processos educacionais é um desafio constante, pois a todo o momento o papel do professor é questionado e reestruturado de acordo com os diversos interesses da sociedade moderna. 
A história da profissão nos mostra como o espaço escolar vem sendo muito lentamente transformado em momentos de aprendizagem e desenvolvimento. Da mesma forma que, a figura do professor foi modificando seus princípios, sua função, sua prática e a promoção do saber que possui e/ou que constrói.

No que se refere aos dilemas da licenciatura, Pereira (2000) pontua os seguintes: a separação entre as disciplinas específicas e pedagógicas; as peculiaridades dos cursos com bacharelado e licenciatura; a desarticulação teoria-prática; os cursos noturnos e as disciplinas integradoras.

O estudo que o autor desenvolveu na UFMG sobre os cursos de licenciatura, pode ser também o reflexo da nossa realidade, já que a categoria formada - o professor vem enfrentando dificuldades equivalentes em todos os contextos.

Como forma de analisar o aluno que ingressa na universidade a pesquisa do autor busca construir o perfil do vestibulando aprovado nos cursos de licenciatura, a partir disso percebeu-se que: os cursos de licenciatura estão entre os menos concorridos e com menos prestígio social; os alunos apresentam idade mais avançada em relação aos demais; são em sua maioria egressos da rede pública; são nas licenciaturas que se enquadram o maior número de egressos do ensino noturno; a renda familiar é inferior dos demais cursos; a maioria dos acadêmicos desenvolve algum tipo de atividade remunerada; a escolaridade dos pais também é inferior dos demais cursos; a ocupação de maior prestígio dos pais não é freqüente nas licenciaturas.

Em relação à representação dos acadêmicos sobre a função do professor evidenciaram-se algumas concepções de ensino. Apesar de a abordagem tradicional estar presente nessa análise, outras concepções mais adequadas ao nosso tempo e as nossas necessidades vem sendo reconhecidas e enfatizadas nos discursos de muitos profissionais.

Sabemos da inegável importância das universidades na evolução do processo educativo, principalmente em se tratando de cursos de licenciatura. Porém, é necessário haver uma reconstrução nos projetos de tais cursos, de forma que estes se efetivem na prática cotidiana. 
Outra transformação que se busca é a desconstrução das relações de poder freqüentes nas universidades. O professor pesquisador é reconhecido como produtor de conhecimentos, enquanto o professor que atua em sala de aula e investe no ensino é o "mero transmissor do saber”. Do mesmo modo que, o ensino na pós-graduação é superior ao ensino da graduação e este último superior ao ensino em cursos de licenciaturas. Além de os professores solicitarem e buscarem muito mais trabalhar com disciplinas específicas, que "transmite" o conhecimento científico da área, do que a prática educativa em disciplinas pedagógicas. Lüdke (1994 apud PEREIRA, 2000, p.38) enfatiza a ordem hierárquica instalada na academia universitária no momento que "o poder vai claramente decrescendo à medida que se troca a atividade de pesquisa pelo ensino ou qualquer coisa relacionada com a educação”.

Assim, nos anos 90 começa-se a pensar no professor que ensina e ao mesmo tempo faz pesquisa, como forma deste profissional formar-se enquanto investigador da sua própria prática e reconstruir constantemente sua atividade e seus saberes docentes. Sendo que, “a formação do professor começa antes mesmo de sua formação acadêmica e prossegue durante toda a vida profissional” (SANTOS apud PEREIRA, 2000, p.49).

A formação profissional docente necessita voltar olhares e tomar como ponto de partida à prática social do acadêmico, pois ele não é um ser a-histórico, a-temporal, mas carrega consiga marcas de suas vivências como aluno. Problematizar suas representações, com foco no contexto escolar e com uma sólida fundamentação teórica, é imprescindível para este perceber-se como professor. Essa perspectiva pode ser um caminho para uma formação de professores com um enfoque no aprender a ser professor e na reflexão sobre a profissão docente (BERNARDI, 2007).

Dessa forma, o professor formador tem um duplo desafio. Necessita trabalhar a representação dos alunos na busca de uma formação reflexiva e ressignificada, ao mesmo tempo em que coloca para si esse desafio. Pois muitas vezes, precisa desenvolver aspectos formativos que não foram ressignificados em seu processo de ensino.

Gadotti (1999) argumenta que no atual contexto educacional, existe uma tendência que remete para o deslocamento da formação puramente individual para o social, político e ideológico. Nesta direção, Manacorda (2000) alerta que nenhuma batalha pedagógica pode ser separada da política e social. 
Nesse sentido, as perspectivas universais de Educação residem no entendimento de que esta deverá se estender por toda a vida dos indivíduos, sendo ainda multicultural, ou seja, levando em conta as diversidades culturais. Argumenta ainda, que ela busca tornar os conteúdos significativos para a vida do aluno (GADOTTI, 1999).

Neste cenário, com tantas mudanças, tanto no âmbito educacional, como nas relações da sociedade, surge um novo fenômeno, o qual Hall (2005), caracteriza como sendo a crise de identidade, ou seja, velhas identidades que por um longo período estabilizaram o mundo social estão em declínio, dando origem a novas identidades fragmentando o homem moderno, que até então era visto como um sujeito unificado.

Concebendo esta nova sociedade, as influências da globalização, é preciso que a Educação supra as novas necessidades que se fazem presente na escola no desenvolvimento dos educandos. Entretanto, percebe-se que pelas escolhas que essa mesma sociedade vem fazendo, não estamos tão perto de atingir esse objetivo. Ainda que, muitos educadores e outros profissionais venham desempenhando um excelente trabalho para alcançar essas metas, a maioria não às fazem.

Dessa forma, o profissional da área de Educação tem sobre si a exigência da construção e socialização de conhecimentos, habilidades e competências que permitam sua inserção no cenário complexo do mundo contemporâneo com a tarefa de participar, como docente, pesquisador e gestor do processo de formação de crianças, jovens e adultos. Nesta direção Chenet; Oliveira (2007, p.3) coloca que "conhecer-se enquanto professor e compreender os próprios processos formativos, com participação crítica e compromissada com a Educação constituem-se em fatores indispensáveis ao processo de formação”.

\section{A PESQUISA EDUCACIONAL}

Para Dalarosa (2000) a pesquisa é um meio de construir conhecimento; uma investigação para solucionar um problema, sendo que existe uma ordem de prioridade em que se faz ciência (fim), pela pesquisa (processo) e com metodologia (caminhos). 
Ao situar a Educação no contexto da pesquisa realiza-se uma reflexão bastante recente, pois esta ganhou foco há pouco tempo em relação aos estudos que vem sendo realizados na área das ciências naturais. Este fato justifica-se de certa forma pela fala de Ferreira (2007) ao dizer que ainda no período imperial no Brasil não havia projeto amplo de Educação, políticas seqüências em prol da escola para todos, muito menos um Estado que investisse seriamente na ampliação e qualificação do sistema educacional. Ainda com o advento da República, as iniciativas foram superficiais e muito relacionadas à política, em vez de um efetivo investimento social.

Assim sendo, não é em vão que as questões referentes à melhora da qualidade dos meios sociais e educacionais caminham tão lentamente, e são colocados em segundo plano pelas autoridades do nosso país.

Nesse sentido, as pesquisas iniciaram abordando temáticas referentes à área das ciências naturais através da criação do método científico, sendo este constituído no contexto de um movimento com origem nos séculos XVI e XVII. Ele valorizava a capacidade do pensamento racional, com o objetivo de ajudar a construir uma representação adequada das questões a serem estudadas (OLIVEIRA, 1998). A partir do ideal de pensamento racional, acreditava-se que pelo uso da razão, seria possível ao homem além de conhecer o mundo, também transformá-lo.

Sendo assim, tratou-se de se criar meios confiáveis para observar, promover experimentos, além de elaborar hipóteses e princípios. Para operacionalizar o método, colocase em evidência a figura do sujeito do conhecimento, este seria, portanto, alguém com existência corpórea, desejoso de fazer valer sua formação científica para elaborar um saber que não só fosse capaz de dar explicações convincentes sobre determinadas questões sociais, mas que, sobretudo pudesse ser aplicado para interferir no rumo das coisas.

O desenvolvimento metodológico se torna fundamental, e a produção do saber se consagra como fonte de poder, surgindo uma união entre conhecimento e política. Deste modo, a política e a ciência recebem enfim o reconhecimento generalizado como instrumentos capazes de promover o domínio da natureza e de disciplinar os homens a lógica da produtividade e da acumulação. Os homens da ciência passam a ser considerados como figuras poderosas e dominadoras. 
No caso das ciências humanas surge uma questão, visto que, é do homem que se trata, ele se torna ao mesmo tempo, sujeito e objeto na investigação científica. A partir de tal fato, o sujeito do conhecimento é conduzido a olhar a sociedade como quem a vê de fora, de longe, ostentando olímpica exterioridade. É, portanto, a mortificação do objeto. Os homens transformam-se em objetos inertes, e aí se inicia a ilusão de que de um lado há os fatos e de outro a teoria. Desta forma, a pesquisa nas ciências humanas necessita ser cuidadosa e zelar para que os homens concretos, sujeitos e objetos de suas indagações, não sejam mutilados.

Portanto, é possível, a necessidade de se reavaliar criticamente as relações entre sujeito e objeto do conhecimento, tendo em vista uma recusa do autoritarismo da verdade, ou seja, a relativização da figura soberana do sujeito do conhecimento, que determinados métodos evidenciam.

\section{A EDUCAÇÃO FÍSICA E SEU CONTEXTO HISTÓRICO}

No que tange a Educação Física, a sua história no Brasil oferece subsídios que ajudam a entender como os professores de Educação Física atualmente reproduzem, em seu cotidiano, ideais e valores do final do século XIX, período a partir do qual a atividade desenvolveu-se no país e foi grandemente influenciada pela chamada Medicina Higienista.

Ao longo do processo de construção da Educação brasileira, a Educação Física foi responsabilizada por cumprir papéis que eram pertinente à determinada época. Por exemplo, nas quatro primeiras décadas do século XX, foi marcante a influência dos Métodos Ginásticos e da Instituição Militar. Nesse Período, a mesma era entendida como atividade exclusivamente prática, fato este que contribuiu para não diferenciá-la da instrução física militar. Outra função foi estabelecida pelo surgimento da educação higienista, a qual determina a Educação Física como meio de construção do homem saudável.

Tais funções atribuídas a Educação Física Escolar nesses períodos históricos, são desenvolvidas até hoje na escola, e ainda defendidas pelos próprios educadores. Entretanto, esta questão seria outro tema de discussão, visto que muitos destes professores formaram-se pelo modelo de racionalidade técnica, que predominavam a prática esportiva, o desempenho, entre outros. 
Assim, a contribuição almejada concretiza-se no sentido de ampliar a visão das pessoas que vem a Educação Física como sendo alienada e descomprometida com a função educativa. Pois, o movimento humano é apenas o meio que fazemos uso para alcançarmos o fim e objetivo desta na escola, a Educação e o conhecimento da área.

Ainda que, seja meta da Educação Física desenvolver aspectos motores e físicos, porém o desenvolvimento cognitivo e psicossocial também fazem parte do rol de conteúdos a serem trabalhados.

Dessa forma, cabe a nós educadores transformar esse entendimento limitado das funções da Educação Física, já que o Estado e as políticas educacionais só buscam manter seu sistema vigente, com a população desinformada e acrítica da real situação em que vivemos.

Somente a partir do início da década de 1980, com a redemocratização do país, é que a Educação Física começou a ser discutida de forma mais contundente, levando ao reconhecimento de que sua prática escolar é problemática e visando a uma redefinição de seus objetivos, conteúdos e métodos de trabalho.

Como salienta Moro (2003) a Educação Física tem buscado superar uma grande lacuna em seus espaços de vivência profissional, caracterizada por um descomprometimento com o conhecimento acadêmico. O cultivo de valores culturais físicos, apropriados e cultuados pelo indivíduo em seu cotidiano, como designo natural ou divino, o tem distanciado das outras necessidades e possibilidades acadêmicas de se estabelecer para e sobre a Educação Física. Nesse sentido, entende-se ser o conhecimento da Educação Física algo que deva ser tratado com discernimento e responsabilidade científica e educacional.

Nessa linha de pensamento, Costa (1994) entende que a formação inicial em Educação Física é o período em que o futuro profissional adquire os conhecimentos científicos pedagógicos e as competências necessárias para enfrentar adequadamente a carreira docente.

No entendimento de Barros (1995) a licenciatura em Educação Física é voltada para a preparação profissional no ensino fundamental e médio, onde é enfatizado o conhecimento da motricidade humana aplicada ao fenômeno educativo, sendo este profissional com formação de nível superior e conhecimento da área a fim, devendo possuir uma visão da função social da escola, de sua história, problemas e perspectivas da sociedade brasileira. 
Esta categoria profissional precisa compreender-se de forma mais abrangente, evitando reduzir-se a uma dimensão mais técnica. Então, torna-se necessário examinar suas atribuições no contexto, que deve refletir o projeto histórico da sociedade.

De acordo com Isaía (2005), o contexto em que o professor se encontra, seja social, cultural, político e educacional leva a entendê-lo em um cenário em que as expectativas e a valorização social; as condições formativas iniciais e o exercício continuado ao longo da carreira entre outros, podem levar ou não ao reconhecimento de uma identidade coesa e autêntica. A riqueza da trajetória está nas oportunidades que cada professor possui nas especificidades da sua área. Então, os professores devem se valorizar, fazendo com que os alunos se interessem pela disciplina.

Nesse sentido, o professor, como qualquer outro profissional, precisa estar constantemente revendo suas práticas pedagógicas, e neste “ir e vir” é que está à possibilidade de reconstruir sua atitude docente, como também, o contexto em que atua, principalmente quando tem a possibilidade de estar trocando, conversando, com os demais professores.

\section{A BUSCA PELA IDENTIDADE DA EDUCAÇÃO FÍSICA}

De acordo com o entendimento de Pimenta (2002) a identidade não é um dado imutável ao mesmo tempo não se configura como algo externo, podendo ser adquirido. Ela nada mais é que um processo de construção de sujeitos ou demais, historicamente situados.

A questão de identidade, tanto da Educação Física foco do estudo, como dos seres humanos e/ou profissionais é bastante polêmica e complexa. No entanto, torna-se necessário desvelar algumas reflexões e discussões que vem sendo realizadas.

Santin (2001) trata muito bem dessa questão ao dizer que os cursos universitários possuem duas fontes fundamentais que os direcionam: a cientificidade e a demanda social.

No primeiro caso, refere-se em repassar determinado conhecimento, este que em determinados cursos confunde-se com a própria ciência, como a física e química, por exemplo. Já o segundo, diz respeito aos serviços que a sociedade precisa fornecer há 
determinadas áreas de sua atuação. Ou seja, nas áreas da saúde e educação as demandas sociais definem o perfil de cada curso. A demanda educacional criou os cursos de licenciatura, com a função de formar profissionais para atuarem nas instituições de ensino.

Entretanto, áreas um tanto quanto indefinidas (para alguns) como a Educação Física, vem promovendo perguntas como: Qual a identidade da Educação Física? Ela é uma ciência?

Em primeiro lugar, a Educação Física “pura” é aquela desenvolvida na escola. Fora dela, podemos chamar de “atividade física”, “exercício físico”, mas a sua identidade possui suas raízes no âmbito educacional. É relevante destacar a colocação de Barbosa (2001, 15) “a Educação Física é uma disciplina que traz em seu nome, em sua identidade e identificação, o termo, a proposta, o compromisso com a educação”.

No que se refere a sua cientificidade, acredito e concordo com Santin (2001) que a mesma não é uma ciência, porém se utiliza de várias ciências para fundamentar sua prática pedagógica na escola.

\section{A PESQUISA NA EDUCAÇÃO FÍSICA}

Gamboa (1994) em seu artigo "Pesquisa em Educação Física: as inter-relações necessárias" realiza algumas considerações no que se refere aos novos campos de conhecimentos epistemológicos.

O autor relata que a Educação Física, juntamente com outras áreas do conhecimento, estão se desenvolvendo no mesmo patamar que definem seus campos epistemológicos no âmbito científico. Sendo que, todas elas são reconhecidas pela Academia e tiveram seu desenvolvimento próprio de acordo com seu contexto, adquirindo assim, sua independência. O reconhecimento destas ciências efetivou-se através das necessidades e prioridades que o desenvolvimento das sociedades solicita, tendo como pressuposto para serem reconhecidas, a pesquisa científica, a reflexão crítica e a vigilância epistemológica sobre seus procedimentos e resultados. 
Atualmente há uma preocupação com a definição dos pressupostos epistemológicos da Educação Física (BRACHT, 1992 apud GAMBOA, 1994). Neste momento o autor destaca três questões básicas a serem analisadas:

\section{- A flutuação do predomínio do enfoque da Educação Física, ora nas ciências} naturais, ora nas ciências humanas: a preocupação de se realizar um diagnóstico sobre as perspectivas da Educação Física demonstra o avanço da área na passagem de questões instrumentais, técnicas e metodológicas para as teóricas e epistemológicas. Pois, pesquisar sobre Educação Física é ir além da utilização de instrumentos, e da realização de procedimentos, mas sim, elaborar referenciais teóricos específicos à área estudada, na busca de desvelar a sua identidade epistemológica.

- A classificação das ciências nos campos epistemológicos: os novos campos epistemológicos abrangem a ação e a prática como ponto de partida e de chegada para a produção do conhecimento, dessa forma, seus estatutos científicos pode ser mais bem entendido como ciências práticas ou da ação. No caso, a Educação Física, ao possuir seu objeto próprio como sendo a motricidade humana, tem relativa especificidade, apesar disso é possível à superação da visão tradicional das ciências aplicadas através da criação de uma nova categoria para as ciências.

- A natureza da Educação Física: sua natureza se fundamenta num tipo específico de Educação, pois se situa mais próxima da articulação existente entre as atividades e processos que desenvolvem a natureza bio-física e humana.

Tendo como base as discussões anteriores, pode-se pensar em alguns desdobramentos da pesquisa na área da Educação Física. Partindo da premissa básica de que a pesquisa e a produção do conhecimento atrelam-se a algumas categorias, uma delas refere-se às abordagens, que se diferem umas das outras de acordo com suas concepções de homem.

Silva (1990 apud GAMBOA, 1994) analisa a produção científica em cursos de Pós-Graduação em Educação Física, e percebe uma predominância em estudos vinculados aos paradigmas empírico-analíticos. Nessa perspectiva, o homem é tomado como um indivíduo isolado, sendo assim a Educação Física é reduzida a efeitos anátomo-fisiológicos. 
No entanto, esta é entendida ainda como um meio de Educação, pois integra o sistema Educativo brasileiro, na medida em que assume a responsabilidade do desenvolvimento harmônico do indivíduo. Concepções de esportes associadas à técnica, rendimento, e à saúde e sua melhora e/ou manutenção também se inserem no âmbito da Educação Física.

Santin (1987 apud GAMBOA, 1994) propõe uma abordagem filosófica de corporeidade ao relatar que o homem é corporeidade, é movimento, é expressividade, neste espaço está a Educação Física. Percebendo que o corpo está vinculado a muitas áreas do saber humano.

Outra tendência é a abordagem crítico-dialética que possui sua matriz no materialismo histórico e a filosofia da práxis. Sua compreensão de homem é entendida como este sendo um sujeito social transformador da natureza e da sua própria natureza, construtor de seu destino, movido por interesses emancipatórios da luta por melhores níveis de vida e de liberdade, é práxico.

Com a criação de cursos de Pós-Graduação em Educação Física no Brasil (Mestrado e Doutorado) na década de 80, a produção científica da área avançou. Neste período, predominavam estudos de ordem empírico-analíticas, tendo em vista que, na década de 90 houve a inserção de diferentes discursos pedagógicos, filosóficos e sociais, onde o momento era propício para ocorrerem mudanças no âmbito científico ao encontro de estudos com abordagem qualitativa (LÜDORF, 2001).

A predominância de pesquisas no paradigma citado anteriormente, se justifica de certa forma, pelas bases epistemológicas da Educação Física. Esta que evidenciava aspectos relacionados com a saúde, militarismo e esporte de rendimento. No entanto, sabe-se que a área abarca bem mais, como por exemplo, questões pedagógicas, culturais, antropológicas, filosóficas e sociais.

A autora se fundamenta em diversos teóricos para embasar a importância da pesquisa para o desenvolvimento profissional dos professores, considerando esta como essencial para o enriquecimento do trabalho docente. Lüdorf (2001) em seu estudo sobre panorama de pesquisas em Educação Física na década de 1990 utiliza a classificação idealizada por Faria Jr. (1992) que se baseia em Gamboa (1989), definindo os seguintes tipos 
de pesquisa: abordagens empírico-analíticas, fenomenológico-hermenêutica e críticodialéticas. Para a análise dos resultados foi realizada a classificação dos resumos de dissertações e teses em função das principais características relacionadas aos tipos de pesquisa.

A partir desta constatou-se que, as abordagens empírico-analíticas ainda prevalecem nas produções científicas da Educação Física, contudo, de forma menos absoluta em comparação aos resultados de estudos anteriores. Sendo verificado um significativo crescimento das abordagens fenomenológico-hermenêuticas, representando uma nova tendência de desenvolvimento das pesquisas de caráter qualitativo. No entanto, a linha críticodialética ainda não está sendo incorporada de forma equivalente com as outras duas abordagens.

Dessa forma, pode-se concluir que apesar da mudança não representar uma transformação nos enfoques de pesquisa, já remetem para um avanço ao encontro de novas propostas metodológicas de pesquisa qualitativa.

\section{PALAVRAS FINAIS}

Educação não é um termo que surgiu há poucas décadas, mas ao contrário, esta se fez presente durante toda a trajetória da humanidade. Independente do período histórico, o ato de educar permaneceu em todas as sociedades, claro que possuindo características próprias com significados diferentes. Nos últimos tempos, não somente o termo Educação vem sendo muito questionado, mas também todos os elementos que constituem o ato de educar. Ou seja, questiona-se o ensino, o professor, a formação de professores, a escola e todos os mecanismos que interagem neste contexto, tendo em vista a necessidade de se responder às angústias e indagações que a sociedade a todo o momento faz. Além da tentativa de se promover uma Educação que acompanhe os novos desafios da sociedade moderna.

Ao abordar questões relativas ao contexto educacional, tem-se uma imensa responsabilidade para embasar os inúmeros aspectos que perfazem seu meio e sua história. Assim, tentou-se abranger o contexto da formação e da pesquisa, considerando o entendimento desses caminhos epistemológicos essenciais para se atingir um objetivo tão almejado por nossa sociedade, a qualidade da Educação. 
Tendo em vista a situação que se encontra a Educação brasileira, os cursos de licenciatura vêm acompanhando esse processo lento de mudança. Porém, nós temos a incumbência e a responsabilidade de assumir a luta pela qualificação desses cursos formativos, já que, de alguma forma fomos beneficiados com eles e hoje desfrutamos de uma pós-graduação gratuita e de qualidade.

É importante destacar que, se parece inviável conquistarmos grandes resultados no âmbito educacional, existe sim, a possibilidade de interferimos e desequilibrarmos o tradicional, o instituído, o hegemônico, através da atuação docente e da gestão escolar, pois, dessa forma estaremos contribuindo com as armas que ainda nos permitem utilizar.

\section{REFERÊNCIAS}

BARBOSA, C. L. A. Educação Física Escolar: as representações sociais. Rio de Janeiro: Shape, 2001.

BARROS, J. M. C. Formação universitária em Educação Física. In: V Simpósio de Pesquisa em Educação Física. Anais. Florianópolis: UFSC, p.13-16, 1995.

BERNARDI, A. P. et al. Formação Profissional em Educação Física e modelos de Desenvolvimento Profissional de Professores. In: II Seminário de Epistemologia em Educação Física Escolar. Anais... Santa Maria, 2007.

CARREIRO DA COSTA, F. A. A. A Formação de Professores: objetivos, conteúdos e estratégias. Revista da Educação Física/UEM, n. 5 (1), p.26-39, 1994.

CARVALHO, A.S. Metodologia da entrevista: uma abordagem fenomenológica. Rio de Janeiro: Agir, 1987.

CHENET, N.; OLIVEIRA, V.F. Os processos formativos em três gerações de professores formadores. Anais... In: II Seminário Nacional de Formação de Professores. Santa Maria, 2007.

CUNHA, M.I. Globalização, educação e formação docente. Educação e Linguagem. Ano 7, v.1, n.9. São Bernardo do Campo: UMESP, jan./jun., p.145-158, 2004.

DALAROSA, A. A. Ciência, Pesquisa e Metodologia na Universidade. In: LOMBARDI, J.C. (Org.). Pesquisa em educação: história, filosofia e temas transversais. 2ed. Campinas: Autores Associados/ Caçador: HISTERDBR-UnC, p.95-104, 2000. 
FERREIRA, L.S. A pesquisa educacional no Brasil: tendências e perspectivas. Material didático da disciplina Enfoques de Pesquisa do curso de Especialização em Gestão Educacional do CE/UFSM. Santa Maria, 2007. 10p.

FREIRE, P. Pedagogia do oprimido. 45. ed. Rio de Janeiro: Paz e Terra, 2007.

GADOTTI, M. História das idéias pedagógicas. 8. ed. São Paulo: Ática, 1999.

GARCÍA, C.M. Formação de Professores: para uma mudança educativa. Porto: Porto Editora,1999.

GÓMEZ. P. O pensamento prático do professor: a formação do professor como profissional reflexivo. In: NÓVOA, A. (Org). Os professores e sua formação. Lisboa: Dom Quixote, p.93-114, 1992.

HALL, S. Identidade cultural na pós-modernidade. Rio de janeiro: DP\&A, 2005.

ISAÍA, S.M. de A. O professor do ensino superior: no entrelaçamento da trajetória pessoal com a profissional. Anais... In: I Seminário Internacional: Pessoa Adulta, Saúde e Educação. Porto Alegre: PUCRS, 2005.

LÜDORF, S.M.A. Panorama da pesquisa em Educação Física da década de 90: análise dos resumos de dissertações e teses. Anais... In: CONBRACE, XII, 2001. Caxambu, 2001. Disponível em: <http://www.cefd.ufrj.br/posgrad/>. Acesso em: 16 abr. 2007.

MANACORDA, M.A. História da Educação: da antiguidade aos nossos dias. 8. ed. São Paulo: Cortez, 2000.

MORO, R. L. Criação e Avaliação de aulas de Educação Física: princípios do "Ensino com pesquisa”. Santa Maria: O autor, 28 de março de 2003. Artigo da disciplina de Fundamentos da Educação Física.

OLIVEIRA, P. S. Caminhos de construção da pesquisa em ciência humanas. In: OLIVEIRA, P.S. (Org.). Metodologia das Ciências Humanas. São Paulo: Hucitec/UNESP, 1998.

PIMENTA, S.G. Formação de professores: identidade e saberes da docência: In: PIMENTA, S.G. (Org.). Saberes pedagógicos e a atividade docente. 3. ed. São Paulo: Cortez, p.15-34, 2002.

PEREIRA, F. Por uma teoria da pedagogia: pesquisas contemporâneas sobre o saber docente. Ijuí: Ed. Unijuí, 1998.

PEREIRA, J.E.D. Formação de professores: pesquisas, representações e poder. Belo Horizonte: Autêntica, 2000.

SANCHÉZ GAMBOA, S. (Org.). Pesquisa educacional: quantidade-qualidade. São Paulo: Cortez, 1995. 
Pesquisa em Educação Física: as inter-relações necessárias. Campinas: PUCCAMP; UNICAMP, 1994.

SANTIN, S. Educação Física: temas pedagógicos. 2. ed. Porto Alegre: Est. Edições, 2001.

SAVIANI, D. Escola e democracia: teorias da educação, curvatura da vara, onze teses sobre a educação política. 38. ed. Campinas: Autores Associados, 2006.

História da formação docente no Brasil: três momentos decisivos. Caderno de

Educação do CE/UFSM. Santa Maria: Editora da UFSM, 2005.

FRANCIELE ROOS DA SILVA ILHA

Mestranda em Educação.

Especialista em Educação Física Escolar e

Gestão Educacional na UFSM.

E-mail: franciele.ilha@yahoo.com.br

Recebido em: 20/07/2008

Publicado em: 31/01/2009 